\title{
Mudanças climáticas e a encíclica laudato sí à luz do pensamento complexo
}

\author{
Izabel Petraglia* \\ Marcel Sena Fernandes** \\ Mariangelica Arone ${ }^{* * *}$
}

\section{Resumo}

Neste artigo, que recorreu a fontes de natureza bibliográfica e documental, apresenta-se o documento Laudato Si para discutir crise ecológica e mudanças climáticas, tendo como referência teórica o pensamento complexo, de Edgar Morin. Parte-se da premissa de que a Encíclica é um pedido aos homens dos tempos atuais no cuidado com a casa comum, a terra. O objetivo deste estudo é entender como os diferentes conhecimentos da Laudato Si e o pensamento complexo, podem se complementar e apontar alternativas para a crise socioambiental que vivemos. Esse diálogo de saberes faz emergir a rede sistêmica, em que tudo está interconectado e interdependente, instigando assim, uma nova compreensão, a ecologia integral e a ruptura de ideias cristalizadas, a fim do cuidado da casa comum, em que ao homem foi dada a natureza do seu cuidado, cultivo e transformação, o guardião da Criação para a vida de todos.

Palavras-chave: Laudato Si; Casa Comum; Ecologia Integral; Pensamento Complexo; Mudanças Climáticas.

* Pós-doutora pelo Centre Edgar Morin, EHESS/CNRS, Paris. Doutora em Educação pela Universidade de São Paulo (USP/SP). Docente do PPGE/ UMESP - Universidade Metodista de São Paulo e coordenadora do GEPEC - Grupo de Estudos e Pesquisa em Complexidade - cadastrado no Diretório de Grupos do CNPq, junto à Universidade Metodista de São Paulo- UMESP. izabelpetraglia@terra.com.br

** Pesquisador do GEPEC/UMESP - Grupo de Estudos e Pesquisa em Complexidade e Mestre em Educação pela UNINOVE. marcel.sena@bol.com.br

*** Pesquisadora do GEPEC/UMESP - Grupo de Estudos e Pesquisa em Complexidade e doutora em Educação pela UNINOVE. angelicarone@yahoo. com.br 


\section{Climate change and the encyclic laudato sí from the perspective of complex thought}

\section{Abstract}

In this article, using bibliographic and documentary sources, we present the document Laudato Si as a way to discuss ecological crisis and climate change. We also use as theoretical reference the "complex thought", of Edgar Morin. It starts from the premise that the Encyclical is an invite to all humanity to care of the common home, earth planet. The objective of this study is to understand how Laudato Si's different knowledge and complex thought can complement each other and point out alternatives for the socio-environmental crisis we are experiencing. This dialogue of knowledge makes the systemic network emerge, in which everything is interconnected and interdependent. We will demonstrate how an instigating new interpretation, "the integral ecology" collaborate with the rupture of crystallized ideas, and with the care of the common home.

Keywords: Laudato Si; "Common Home"; Integral Ecology; Complex Thought; Climate Changes.

\section{El cambio climático y la encíclica laudato sí a la luz del pensamiento complejo}

\section{Resumen}

En este artículo, que utilizó fuentes de carácter bibliográfico y documental, se presenta el documento Laudato Si para discutir la crisis ecológica y el cambio climático, teniendo como referencia teórica el pensamiento complejo, de Edgar Morin. Se parte de la premisa de que la Encíclica es una petición a los hombres de la actualidad al cuidado de la casa común, la tierra. El objetivo de este estudio es comprender cómo los diferentes conocimientos de Laudato Si y el pensamiento complejo pueden complementarse y señalar alternativas para la crisis socioambiental que vivimos. Este diálogo de saberes plantea la red sistémica, en la que todo está interconectado e interdependiente, instigando así una nueva comprensión, una ecología integral y la ruptura de ideas cristalizadas, para cuidar la casa común, en la que se le dio al hombre la naturaleza de su cuidado, cultivo y transformación, el guardián de la Creación para la vida de todos.

Palabras llave: Laudato Si; Casa común; Ecología Integral; Pensamiento Complejo; Cambios climáticos. 


\section{Introdução}

(...) Estamos num momento crítico da história da Terra, na qual a humanidade deve escolher o seu futuro (...). A escolha nossa é: ou formamos uma aliança global para cuidar da Terra e cuidarmos uns dos outros ou arriscamos nossa própria destruição e a da diversidade da vida (Carta da Terra, Preâmbulo).

A carta encíclica papal Laudato Sí, publicada em 2015, trouxe uma mensagem inovadora: o homem e a natureza são partes do mesmo todo. Embora este conceito não seja novidade para a ciência e para as filosofias ambientais, o é para as religiões do ramo cristão, estruturadas e estruturantes do que chamamos de valores ocidentais, como o cristianismo católico. Partindo do referencial epistemológico da complexidade, de Edgar Morin, buscamos compreender, por meio de pesquisa bibliográfica e documental, este movimento dialógico da igreja católica em favor de um debate ecológico amplo e necessário.

Por entendermos que a questão é atual e que comporta uma urgência própria das questões pertinentes às diversas crises - ambiental, social, econômica, ética e sanitária - que estamos vivendo, interessa-nos articular os conceitos do Pensamento Complexo com as ideias publicadas no documento ecológico da igreja católica de 2015, com vistas a entender se existe e qual é a qualidade de diálogo que se faz possível a partir destes saberes distintos.

O ano de 2020 já figura entre os momentos mais dramáticos da humanidade, seguramente o maior desafio já enfrentado no século XXI. Até o momento desta redação, só o Brasil já contava com mais de 105 mil mortos e ultrapassava três milhões e duzentas mil pessoas infectadas pela Covid- $19^{1}$, doença que se espalhou pelo mundo desde o final de 2019 e levou o planeta a um estado de pandemia, sem precedentes.

1 Disponível em https://covid.saude.gov.br/ Último acesso em 14/08/2020. 
Embora sua origem ainda seja objeto de investigação, sabe-se que se trata de um produto resultante de interações no mundo animal, um produto da natureza ${ }^{2}$. É certo também que nosso modo de vida, há muito tempo, está causando transformações em diversos ecossistemas ao ponto de não mais sabermos o limite das consequências que isso nos traz. O modo de vida em grandes metrópoles e as facilidades tecnológicas de circulação de pessoas e produtos completam o cenário, no qual uma crise, que em outros tempos seria apenas local, se converte rapidamente em um problema de todos os residentes desta nossa casa comum, o planeta Terra.

Estamos sendo alertados, há muito tempo, de que o modo de vida e de produção favoreceria o surgimento de problemas sanitários, ambientais e de sobrevivência que tocariam a todos, sem respeitar nossas fantasiosas fronteiras políticas. Dos movimentos de consciência no século XX às cúpulas do clima ${ }^{3}$, pesquisadores vêm nos alertando para o fato de que precisamos rever nossas formas de produzir, consumir, pensar e viver, pois, arriscamos enfrentar nossa própria extinção como espécie.

Se é verdade que não podemos responsabilizar diretamente a influência do homem no meio ambiente pelo surgimento e propagação da pandemia que enfrentamos, também é verdade que diversos estudos apontam para esta possibilidade no futuro ${ }^{4}$. Sofrimento global é uma realidade no horizonte de uma civilização que não se percebe responsável pela vida que a cerca. A poluição atmosférica, a destruição das florestas, o uso irresponsável dos recursos hídricos, a poluição dos oceanos e a exploração insustentável do solo são vetores que apontam para um futuro incerto, em que dramas como o que estamos vivendo na pandemia, se tornam cada vez mais frequentes.

2 Disponível em https://www.bbc.com/portuguese/geral-52967280 Último acesso em 02/07/2020.

3 Nos referimos aqui às conferências Ambientais de Estocolmo em 72, Rio 92, Rio +10 em Joanesburgo em 2002, Rio + 20 no Rio de Janeiro em 2012 e COP 21 em Paris 2015.

4 Disponível em https://nacoesunidas.org/acao/mudanca-climatica/ Último acesso em 02/07/2020. 
Temos a oportunidade de debater e aprender com a realidade que a pandemia obriga a todos vivenciar, pois algumas destas experiências se repetiriam em outros cenários críticos como projetam estudos sobre as mudanças climáticas. Somos convocados a assumir nossa responsabilidade ética com o próximo, com a comunidade local, internacional e com o planeta.

\section{A pesquisa sobre mudanças climáticas}

Foi com este espírito, de promoção da reflexão e do debate sobre nossas responsabilidades com o futuro e as questões ambientais que aderimos em 2014, por meio do Grupo de Estudos e Pesquisas em Complexidade (GEPEC), atualmente sediado na Universidade Metodista de São Paulo e cadastrado no Diretório de Grupos de Pesquisa, do CNPq, a um projeto de pesquisa em rede internacional ${ }^{5}$ intitulado "Pacto Global de Jovens pelo Clima", com apoio da Unesco, concomitantemente desenvolvido em escolas de São Paulo, no Brasil e em mais 29 países.

No Brasil, o recorte dessa pesquisa tem o tema "Mudanças climáticas na visão de estudantes do ensino médio". O estudo objetivava, em sua primeira fase, sensibilizar e envolver os estudantes em um debate sobre as transformações ambientais, suas responsabilidades, pontos de vistas e propostas de soluções. O material resultante fora encaminhado para a Conferência do Clima em Paris, no final do ano de $2015^{6}$.

O trabalho realizado, por nós no Brasil e nos demais países, tem a base epistemológica assentada no pensamento complexo de Edgar Morin. Do projeto conceitual à metodologia, o Pensamento Complexo norteou nossas ações. É de Morin, a autoria da ideia de reforma do pensamento, que entende que as ações autodestrutivas humanas têm base em uma percepção equivocada e fragmentada da realidade, da qual decorre problemas epistemológicos e consequentemente crises que não conseguimos diagnosticar e superar. A

\footnotetext{
5 Disponível em https://www.globalyouthclimatepact.org/index.php Último acesso em 02/07/2020.

6 Ver https://www.globalyouthclimatepact.org/docs/proposals/2016-pact-brasil_Propuestas-Sao-Paulo.pdf Último acesso em 14 de agosto de 2020.
} 
razão para nossas crises precisa ser problematizada, assim como a exclusividade da ciência como método de compreensão da realidade e das crises.

A ciência, a técnica, a economia, o lucro são os motores desse dinamismo que propulsa a nave espacial Terra. Este dinamismo científico $\urcorner$-técnico-econômico produziu novos perigos para toda a humanidade, com a proliferação das armas nucleares, com a degradação da biosfera, com as policrises planetárias e, também, com os novos conflitos étnico-religiosos que dilaceram nosso planeta e podem provocar a utilização das armas de aniquilamento. Somos testemunhas e vítimas atuais de uma crise econômica decorrente da ausência de regulação de uma economia mundial corrompida pela especulação financeira. Essa crise se inscreve num conjunto de crises. Crise da relação entre os seres humanos e a natureza, como o provam as múltiplas degradações da biosfera. Crise das sociedades tradicionais, que tendem a se desintegrar sob o dinamismo dessa mundialização, que, na verdade, é uma ocidentalização. Crise da própria modernidade, já que não só a modernidade alcançada nos países da Europa ocidental e nos Estados Unidos não cumpriu as promessas de uma vida melhor, de uma vida emancipada, de uma vida harmoniosa, mas, ao contrário disso, criou um novo mal-estar na civilização. (MORIN et al. 2011, p.23)

Em sua obra Morin propõe a necessidade da reforma do pensamento. Em "A cabeça bem-feita: repensar a reforma, reformar o pensamento" (MORIN, 2007), o autor indica com ênfase esta necessidade. Uma reforma que supere os reducionismos que impedem a compreensão da complexidade da realidade, do ser humano, e suas múltiplas relações e inter-relações.

Para o enfrentamento da crise ambiental, Morin propõe um Pensamento Complexo (2007, p. 19): “A reforma necessária do pensamento é aquela que gera um pensamento do contexto e do complexo. O pensamento contextual busca sempre a relação de inseparabilidade e as inter-retroações entre qualquer fenômeno e seu contexto, e deste com o contexto planetário". E, continua, o autor:

O complexo requer um pensamento que capte relações, inter-relações, implicações mútuas, fenômenos multidimensionais, realidades que são si- 
multaneamente solidárias e conflitivas (como a própria democracia que é o sistema que se nutre de antagonismos e, que, simultaneamente os regula), que respeite a diversidade, ao mesmo tempo que a unidade, um pensamento organizador que conceba a relação recíproca entre todas as partes. (MORIN, 2007, p. 19-20).

Ao concluir a primeira etapa, da pesquisa sobre mudanças climáticas em 2015, vivemos as angústias e dificuldades para colocar as transformações necessária em prática, pois sempre esbarrávamos em dois fatores limitantes. Primeiramente o interesse econômico, que sustenta o modelo em que vivemos, que não está interessado em questões como as que foram levantadas em nosso trabalho, e tem força suficiente para retardar o debate e as transformações.

Outro obstáculo que se encontra mais perto de nós, é a dificuldade de mobilizar as pessoas ao nosso redor para que elas se conscientizem e que se tornem agentes da mudança necessária pelo bem do meio ambiente. Muito além da falta de informação, existe ausência de percepção, responsabilidade e senso de urgência.

Os debates climáticos fortalecidos marcantemente a partir das conferências internacionais dos anos 90 vêm enfrentando dificuldades de transformar pesquisas científicas em ações práticas que emergem da conscientização. Quase trinta anos depois da Eco 92, no Rio de Janeiro, os avanços são modestos e a ciência não alcançou seu objetivo de diminuir o aquecimento global, passando a ser objeto de desconfiança por alguns grupos políticos quando o assunto é mudança climática. Era preciso tentar novas abordagens.

\section{Louvado sejas}

No mesmo ano em que ocorreu a Conferência do clima de Paris, 2015, a Igreja Católica publicou a encíclica ${ }^{7}$ Laudato Sí, Louvado sejas em italiano. Um documento papal tradicional da fé cristã, que versa sobre as emergências eco-sociais e temas correlatos.

Encíclicas são documentos pontifícios que funcionam como cartas abertas do chefe da igreja Católica, destinada a um público determinado com um termo específico. 
Esta atualização moral de uma instituição cristã convoca seus fiéis a perceberem que "tudo está interligado" em uma "casa comum" e propõe mudanças de atitudes a partir de uma concepção de "ecologia integral"8. Aqui pontuamos que o conceito de integralidade, essencial na estrutura da carta papal, se aproxima do pensamento complexo ao mesmo tempo em que se distancia, uma vez que a complexidade não concebe as noções de totalidade ou integralidade, mas entende que o todo é, ao mesmo tempo, maior e menor que a soma de todas as partes (MORIN, 2007a; PETRAGLIA, 2001).

Sua metodologia é inovadora e coerente com os postulados que o Papa Francisco tem advogado desde o início de seu papado. Durante a "V Conferência Geral do Episcopado da América Latina e do Caribe", realizada em 2007 na cidade de Aparecida, Brasil, elaborou-se o que ficou popularmente conhecido como "Documento de Aparecida", no qual apresentava uma metodologia nova para a Igreja Católica conduzir as suas reflexões e ações teológicas. O método consiste nos conceitos de "Ver, Julgar, agir e Celebrar".

É importante notar que a teologia proposta não parte de uma abstração teórica idealizada para depois ser aplicada à realidade, mas de uma observação da vida e dos casos concretos que nos cercam para em seguida avaliar e agir. A ação também se torna parte importante da metodologia, entendendo que sem a ação, a celebração não se faz possível e a teologia não se faz completa.

Pensando nos princípios do "ver, julgar e agir", a encíclica é então estruturada em 6 capítulos. O primeiro capítulo é uma descrição do que se percebe acontecer hoje com o planeta, em crise ambiental. No capítulo seguinte o Papa se dedica a amparar a reflexão ecológica nos textos bíblicos. Nas duas partes que seguem, Francisco discute tanto as raízes da crise ecológica quanto um modelo holísti-

\footnotetext{
8 Ecologia Integral, entendida, como "uma ecologia que, nas suas várias dimensões, integre o lugar específico que o ser humano ocupa neste mundo e as suas relações com a realidade que o rodeia" (LS15, p.14)

9 Disponível em https://www.a12.com/source/files/originals/Documento_ de_Aparecida_2017.pdf Último acesso em 02/07/2020.
} 
$\mathrm{CO}^{10}$ de se olhar para a ecologia. Nas partes finais, a encíclica se dedica a traçar linhas orientadoras de ações necessárias, e discute ainda a importância de uma educação e uma espiritualidade ecológicas.

É preciso pontuar que a Igreja Católica Apostólica Romana é uma das mais antigas instituições do ocidente ainda em atividade. Em seus quase dois milênios de existência, participou ou foi responsável por momentos históricos dramáticos, polêmicos e fundamentais para a criação da identidade e do imaginário ocidental que partilhamos hoje. Com aproximadamente 1,3 bilhão de fiéis declarados pelo mundo em $2016^{11}$, seu alcance político e sua autoridade moral entre os fiéis é um indiscutível instrumento de poder, já usado muitas vezes na história em desfavor das vozes do sul.

Nas últimas décadas a Igreja tem vivido movimentos de revisão em diversos assuntos. O tema da ecologia não é exatamente uma novidade para o cristianismo católico. Em outros documentos papais, os Papas Paulo VI, João Paulo II e Bento XVI também abordam as questões ambientais, em geral, de modo pontual. Uma novidade celebrada pelos ambientalistas, no entanto, é que a nova encíclica aborda a questão ambiental como uma questão sistêmica, e incorpora valores dos movimentos que defendem a necessidade de mudanças paradigmáticas na relação do homem com o meio ambiente.

A Laudato Si, se encaixa nestes movimentos, tendo sido publicada com duras críticas ao sistema socioeconômico hegemônico e responsabilizando o homem e seu modo equivocado de vida pela crise ambiental que enfrentamos.

A Igreja Católica, com este movimento, entra definitivamente para o debate ambiental. Por caminhos racionais, mas também

$10[\ldots]$ a perspectiva holística não significa o somatório dos pontos de vista (que são sempre a vista de um ponto), mas a capacidade de ver a transversalidade. Quer dizer, a capacidade de detectar os interretrorrelacionamentos de tudo com tudo. Economia, gestão e cálculo têm a ver com filosofia, física, arte e religião. Nada existe justaposto ou desvinculado do todo. (BOFF, 2010, p.98).

11 Disponível em https://www.vaticannews.va/pt/vaticano/news/2018-06/ anuario-pontificio-2018-annuarium-statisticum-ecclesiae.html Último acesso $02 / 07 / 2020$. 
teológicos e espirituais na crítica e na proposta de ação, o que encontramos é uma iniciativa que apresenta a virtude da dialogia, ao mesmo tempo em que oferece novas ferramentas para o trabalho de conscientização ambiental, por métodos e instrumentos próprios das religiões. Uma iniciativa em momento oportuno, e que se aproxima das propostas da Complexidade em seus diversos aspectos.

\section{Aquilo que foi separado artificialmente}

Cabe-nos ainda pontuar um movimento de aproximação entre ciência e religião, tão caro ao pensamento complexo. Trata-se de uma relação com grande carga simbólica, sobretudo ao ocidente, e que passamos a contextualizar.

O tema ciência e religião se apresenta ao mundo de hoje a partir de fontes, metodologias e sistemas de saberes próprios, que os diferenciam e até os distanciam. Mas o lugar destas ideias nem sempre foi tão apartado na história do pensamento ocidental.

Stephen F. Manson, em sua obra "História da Ciência" (MANSON, 1964), nos ensina que no princípio das civilizações ocidentais a investigação e o avanço das técnicas eram conduzidos pelos clérigos. De modo geral, alguns sacerdotes na mesopotâmia, Egito antigo e Grécia antiga ocupavam os papéis de estudiosos das questões que suas crenças lhe incumbiam. Assim, o comum era que, por exemplo, um sacerdote de um Deus da colheita, também observasse e estudasse os elementos envolvidos na agricultura, assim contribuindo para o avanço das técnicas agrícolas ao mesmo tempo em que contemplavam as dimensões espirituais e culturais relativas à arte de prover o alimento.

Os pré-socráticos, como Pitágoras (sec. V a.c.), dedicavam-se comumente à razão matemática ao mesmo tempo que meditavam sobre questões místicas e filosóficas. Assim como a lógica dialética e pensamentos platônico-aristotélicos influenciaram os primeiros séculos da teologia cristã na Europa, estando presentes nas obras de Santo Agostinho (sec. III) e São Tomás de Aquino (sec. XIII). A partir de 1088 d.C. a igreja católica foi responsável pela criação das 
primeiras Universidades, com o modelo de investigação científica. Entretanto, quando as ideias conflitavam com seus dogmas a Igreja comprometia o avanço da ciência, perseguindo e condenando à morte os precursores do pensamento científico, muitas vezes os obrigando a negar suas descobertas, como nos casos de Galileu Galilei e Giordano Bruno na defesa do heliocentrismo, no século XVI.

Já o pensamento racional-científico se desenvolvia como método, e se apresentava como a única forma confiável de se compreender e prever os fenômenos da vida. De René Descartes (sec. XVII) à Auguste Comte (sec. XIX), a Ciência ganha a dimensão que conhecemos hoje, motivada pelo progresso tecnológico e o sucesso de seus métodos de abordagem. Foi o positivismo filosófico quem classificou as sociedades pela medida do progresso, no qual as civilizações mais racionalistas e cientificistas ${ }^{12}$ eram percebidas como em um estágio superior de evolução em relação às sociedades tradicionais e místicas.

O movimento científico do positivismo, no século XIX, ampliou a autoridade da Ciência nos campos sociais, políticos e econômicos. A partir disso, o lugar dos saberes não científicos se tornaria cada vez menos prestigiado pelas sociedades modernas, até serem, no século XX, excluídas formalmente das práticas acadêmicas e dos critérios de validação das ideias no debate público. A ciência passa a ser não só a referência de verdade, mas também a única autoridade para determinar as verdades. O confiável método científico se acreditava provado nas descobertas das ciências naturais, no sucesso do progresso técnico e seus desdobramentos econômicos, nas revoluções industriais, influenciando, assim, os modelos políticos da idade contemporânea.

Este caminho de poder e autoridade da Ciência nos leva a um paradigma simplificador, em que o saber e a técnica científica ocupam todos os espaços de legitimidade dos saberes, num exercício de poder fragmentado em especialidades concentradas.

\footnotetext{
12 Aqui escolhemos cientificistas ao invés de científicas, na opção de apontar as questões ideológicas que subsidiam o pensamento científico, nem sempre claras a seus destinatários.
} 
Edgar Morin, crítico deste paradigma científico, apontou em inúmeras obras que a Ciência trouxe algo além de progresso e desenvolvimento. Seu método de hiperespecialização dos saberes foi útil ao modelo de produtividade, mas também deixou incomunicáveis os mais diversos campos do saber científico, entre si. Para Morin "o fechamento disciplinar, associado à inserção da pesquisa científica nos limites tecnoburocráticos da sociedade, produz a irresponsabilidade em relação a tudo o que é exterior ao domínio especializado". (MORIN, 2007b, p. 73).

A ciência aperfeiçoa a técnica, que aperfeiçoa a produtividade, que influencia o modelo de produção e acaba direcionando o modo de vida e de consumo. Mas a ciência não se responsabiliza por tudo que produz. A complexidade possibilitou a percepção de que a tendência à fragmentação do saber científico tem como resultado uma tendência ao anonimato. O saber não é pensado, meditado, refletido e discutido por seres humanos, numa busca por conhecimento e sabedoria, mas acumulado em bancos de dados para ser computado por instâncias que muitas vezes instrumentalizam e até manipulam estes dados.

Assim há: - progresso inédito dos conhecimentos científicos, paralelo ao progresso múltiplo da ignorância; - progresso dos aspectos benéficos da ciência, paralelo ao progresso de seus aspectos nocivos ou mortíferos; progresso ampliado dos poderes da ciência, paralelo à impotência ampliada dos cientistas a respeito destes mesmos poderes. (MORIN, 2010, p. 18)

Para sair desta armadilha, o pensamento complexo propõe uma mudança brusca de método e abordagem, começando pela religação das coisas que foram artificialmente separadas. Pela complexidade, todas as coisas são tecidas em conjunto (MORIN, 2007a). Ao retomar o diálogo com a Religião, dentre outros modos de saber, a Ciência permite espaços novos de construção, onde diferentes elementos possibilitam outros pontos de vista.

A questão da crise ambiental é um sólido exemplo de que as perspectivas e abordagens científicas não dão conta das diversas 
dimensões do problema, além de não compreender como estas dimensões são vividas, experimentadas e sentidas por aqueles a quem se destina o debate. Morin advoga que não devemos separar a razão e a sensibilidade, a ciência e a religião (MORIN, 2010). A reflexão sobre temas tão complexos como o homem, a vida ou a natureza não pode encerrar-se num único modo de percepção. É preciso pensar de modo dialógico, sem a necessidade de uma síntese, nem de uma sobreposição, mas aproveitando as virtudes de cada modo de saber, em convivência reverente, com o objetivo de superar as limitações que também cada modo traz em si, quando isolados.

É fato que a instituição igreja católica já reconheceu e corrigiu muitos de seus erros do passado, não se colocando mais como antagonista do saber científico. Mas também é importante pontuar que uma disputa localizada na história, nos ajudou a chegar ao ponto em que estamos. Uma ciência que concentra muito poder, e que não dialoga com outros campos de saberes não científicos, ao mesmo tempo que não consegue dar conta da compreensão de uma realidade de uma crise complexa ou de um ser humano que também é arte, espiritualidade, paixão, loucura.

Precisamos reabrir os diálogos para aprimorar as nossas percepções sobre as crises em que estamos envolvidos, e que tem em sua raiz um modelo de realidade e de homem, no mínimo, muito lacunar. No sentindo de ampliar esta noção de homem e de mundo, a Laudato Si propõe-se para o enrijecimento das demandas por uma nova abordagem das questões emergentes de nosso tempo.

\section{Estabelecendo o diálogo: a emergência da mãe- -pátria}

O fragmento da epígrafe da Carta da Terra que ilumina esse texto nos remete a necessidade urgente de refletir sobre as questões ambientais, dos valores da pessoa humana e do bem comum, pois atualmente vivemos uma crise sem precedentes. Estamos assistindo aos reflexos das ações dos humanos sobre o desequilíbrio da natureza, e isso vem de longe. 
Tentaremos aqui abrir o diálogo entre abordagens da Encíclica Laudato Si e o Pensamento Complexo, a tempo de contribuir com o avanço dos debates sobre ações coordenadas no enfrentamento das causas da complexa crise socioambiental, ou como indicam Morin e Kern (2011), uma "policrise".

Começamos pela mensagem central Laudato Si (Louvado Sejas), da primeira encíclica do papado de Francisco, escrito em 2015. $\mathrm{Na}$ obra podemos identificar pressupostos complexos de uma frase repetida em muitas páginas: "tudo está interligado". (L.S. p. 71, 91, 107, 182 ).Trata-se de um pressuposto complexo na medida em que não se separa o funcionamento da Terra ou a natureza das ações de cada ser humano, como, ainda, devolve a ele o seu papel de proteção ambiental e de sua vida enquanto protagonista do funcionamento do mundo.

Esse tipo de conhecimento está presente na ideia da Casa Comum, que é aquela que “(...) recordava-nos que a nossa casa comum se pode comparar ora a uma irmã, com quem partilhamos a existência, ora a uma boa mãe, que nos acolhe nos seus braços" (LS, 1, p.3). O texto reporta-nos ainda à religação de nossa composição cósmica: “(...) O nosso corpo é constituído pelos elementos do planeta; o seu ar permite-nos respirar, e a sua água vivifica-nos e restaura-nos" (LS, 2, p.3).

Casa comum é a noção, segundo a qual o ser humano é parte da substância única de todo conjunto e está em relação de interdependência com os elementos da criação. Do ponto de vista que nesse sistema de vida no planeta existe um princípio gerador vital que é a integração indissociável entre a vida humana e o bem-estar de toda a Terra, interpretado como a casa comum.

Em nosso entender, esse ideário pode ser concebido como um reconhecimento de que todos somos parte da Terra e somos convidados a viver a comunidade da vida, pois "nós mesmos somos terra" (LS, 2, p.3). De modo a reconhecer que ao mesmo tempo somos parte da natureza, e somos integrados a ela, assim temos um conjunto de responsabilidades éticas para com ela. 
Isso nos conduz a ideia central da Encíclica, que é a Ecologia Integral, quando coloca o termo no paradigma de união de todos os sistemas complexos, nas várias dimensões de fenômenos e problemas ambientais (aquecimento global, poluição, exaustão dos recursos, desflorestamento, etc.), com questões que requerem a integração da relação das partes entre si e o todo (convivialidade entre a espécie humana, outros seres vivos, comunidade local e nação) .

De modo que "É fundamental buscar soluções integrais que considerem as interações dos sistemas naturais entre si e com os sistemas sociais. Não há duas crises separadas: uma ambiental e outra social; mas uma única e complexa crise sócio-ambiental" (L.S. p. 108). A questão ecológica não aparece separada das outras noções.

O conceito desenvolvido aqui é o da interdependência que se configura nas relações do homem com a natureza e com outros seres humanos, o que inclui ética e cultura. Essas ideias são apontadas e, amplamente discutidas por Morin nos seis volumes de "O método" (2008; 2011a; 2008a; 2011b; 2002; 2007b) e no livro "Terra-Pátria", escrito com a colaboração da jornalista Anne Brigitte Kern (2011), que também nos remete à reflexão de pátria como casa comum.

(...) consciência e sentido de pertença que liga a humanidade com a Terra, considerada como primeira e última pátria. A pátria é o termo masculino/ feminino que unifica nele o maternal e o paternal. Por isso, a ideia de Estado-Nação implica uma substância mitológica/afetiva extremamente "cálida”. O componente matripatriótico dá valor maternal à mãe-pátria, terramãe, para qual se dirige naturalmente o amor e por meio da qual é possível também a fraternidade, como base política para a reunião da diversidade de indivíduos e etnias num mesmo lar. Além disso, oferece a potência paternal ao estado (paipatriarca) ao qual se deve obediência para assim conformar uma unidade política e institucional. A pertença a uma pátria dá lugar à comunidade fraternal de patriotas e de filhos da pátria ante qualquer ameaça externa (MORIN; CIURANA; MOTTA, 2003, p.87-88).

A perspectiva dessa abordagem sobre a terra-pátria nos faz refletir acerca da possibilidade do ser humano pensar e agir em sua 
comunidade de origem que é a mesma de destino, segundo os princípios da ética, base da solidariedade, responsabilidade e compreensão da realidade. Desse modo, "não é a Terra prometida, não é o paraíso terrestre. É nossa pátria, o lugar de nossa comunidade de destino de vida e de morte terrestres. Devemos cultivar nosso jardim terrestre, o que quer dizer civilizar a Terra" (MORIN; KERN, 2011, p. 166).

Só poderemos escutar os apelos que brotam da terra-pátria, na medida em que estivermos disponíveis a aprender a noção da ética, que nos faz pensar nas relações de vida com o outro, a natureza, a comunidade, a humanidade e o cosmo. É o que Morin apresenta no processo de construção da tríade indissociável: Autoética, Socioética, Antropoética.

A Autoética é a dimensão mais individual de ética. É a ética de si:

[...] alimenta-se de fontes vivas - psicoafetivas, antropológicas, sociológicas, culturais - o sujeito sente o apelo do princípio altruísta e o apelo da solidariedade. Mesmo assim, a autonomia ética é frágil e difícil, a partir do momento em que o indivíduo experimenta mais o mal-estar ou a angústia das incertezas éticas que a plenitude das responsabilidades (MORIN, 2007b, p. 92).

Morin nos mostra que a autoética vai se moldando na constituição do sujeito, em seu processo de individuação, e se dá nas interações com a realidade, em sua história e cultura. Trata-se da dimensão ética que se gesta no âmbito da autonomia individual.

A ética do outro, a qual Morin denomina Socioética é também a ética da comunidade ou da sociedade. Para o autor (2007b, p. 151):

(...) se todas as éticas comunitárias são idênticas nos imperativos principais, são extremamente diversas e até mesmo incompatíveis nas suas prescrições particulares, nas obrigações rituais, tabus, códigos de honra. As diferenças indicam-nos que existem mil morais. Mas se consideramos as semelhanças, há só uma, a da comunidade.

Trata-se de uma dimensão ética em cujos princípios reside uma cadeia interdependente, a qual se dá na nossa compreensão 
das relações com o mundo que construímos com os outros, promovendo assim uma ética do conviver. Nessas tessituras simultâneas da autoética e socioética, coloca-se a antropoética, que é a ética da espécie, do homo sapiens que também é homo sapiens-demens.

A Antropoética ergue no nível ético a consciência antropológica que reconhece a unidade de tudo o que é humano na sua diversidade e a diversidade em tudo o que é unidade; daí a missão de salvaguardar por toda a unidade e a diversidade humana. (2007b, p.160).

E, assim, o homem vai tecendo a sua condição humana em seus contextos de existências da própria espécie, com seus traços de vida, de seu mundo histórico, cultural, social, econômico, político. Nessa tríade: autoética, socioética, antropoética busca-se conceber a dimensão de cuidado da vida e do planeta, da política de civilização, da restauração da esperança.

À medida que pensamos na ideia da Ecologia integral da Encíclica, consideramos a aliança da humanidade pela vida, que perpassa pela tríade ética proposta por Morin. Nessa direção compreendemos, que tudo está interligado, num processo complexo. E, refletimos que "as espécies vivas formam uma trama que nunca acabaremos de individuar e compreender. A natureza não pode ser apartada de nós. Estamos incluídos nela, somos parte dela e compenetramo-nos" (CARVALHO,2020, p.61).

\section{Considerações finais}

A Laudato Si trata de mudança de ponto de vista, ao defender uma ecologia integral. Neste sentido, a encíclica aponta para uma abordagem que supera o pensamento linear. Ao mesmo tempo em que propõe mudanças profundas, ela acena para um pensamento complexo. A Laudato Si faz parte de um novo e diferente movimento, que empresta sua força histórica institucional aos modelos complexos de pensamento, que reivindicam transformação paradigmática na humanidade. 
Ao abordar nos primeiros capítulos da encíclica, as perspectivas científicas sobre a questão ambiental, a igreja também faz um gesto em favor do acolhimento do ponto de vista de outro saber, para depois, em conjunto, pensarem soluções de problemas que dizem respeito a todos os seres, sem fronteiras sociais, políticas ou de áreas do conhecimento. Não se trata meramente de buscar um denominador comum, nem de retirar de qualquer das partes a legitimidade ou a autoridade em seu campo específico, mas se trata de um exercício de harmonização entre diferentes modos de percepção sobre uma questão comum. Um retorno ao princípio da história humana, em que as coisas eram tratadas como partes de um mesmo todo. Partes que devem coexistir absorvendo, inclusive, suas diferenças, regulando e mantendo o conflito que faz crescer.

Acreditamos na atualidade e no vigor da Laudato Si, porque acreditamos, como Edgar Morin, em uma nova forma de produzir ciência. Não uma anti-ciência, mas uma ciência com consciência (MORIN, 2010) de sua responsabilidade ética, na medida em que aceita se perceber também limitada. Mais ainda, acreditamos na necessidade de se resgatar os saberes dispersos capazes de contribuir para o repensar do humano e de seus contextos.

Estamos conscientes de que é um exercício que precisa ser ampliado, incluir outras vozes, outras ideias, mitologias, imaginário. Mas estamos satisfeitos por encontrar nesta encíclica os pressupostos da complexidade necessários para se dar os próximos passos na construção de uma nova ciência de convivência, afinal, acreditamos no mesmo sentido que fundamentou a Laudato Sí: somos todos partes de um mesmo todo e responsáveis por ele.

\section{Referências}

BBC. Coronavírus. O que os cientistas já descobriram sobre o covid-19 nos seus 6 primeiros meses. Disponível em: https://www.bbc.com/portuguese/geral-52967280 Acesso em 02/07/2020.

BOFF, L. Ethos mundial: um consenso mínimo entre os humanos. Rio de Janeiro: Record, 2010. 
CARTA DA TERRA. Disponível em https://www.mma.gov.br/estruturas/agenda21/_arquivos/carta_terra.pdf. Acesso em 26/06/2020.

CARVALHO, E. A. Da Crise Ecológica ao pensamento complexo. Entrevista especial com Edgard de Assis Carvalho. REVISTA IHU ON-LINE. Disponível em http://www.ihu.unisinos.br/544956. Acesso em 26/06/2020.

CORONAVÍRUS/BRASIL. Disponível em: https://covid.saude.gov.br Acesso em 14/08/2020.

DOCUMENTO DE APARECIDA. Disponível em: https://www.a12.com/source/files/originals/Documento_de_Aparecida_2017.pdf Acesso em 02/07/2020.

GLOBAL YOUTH CLIMATE PACT. Disponível em: https:/ /www.globalyouthclimatepact.org/index.php Acesso em 02/07/2020.

L. S. IGREJA CATÓLICA. Papa (2013- : Francisco). 'Laudato si': sobre o cuidado da casa comum. Vaticano: Libreria Editrice Vaticana, 2015. Disponível em:

http://w2.vatican.va/content/francesco/pt/encyclicals/documents/papafrancesco_20150524_enciclica-laudato-si.html. Acesso em: 26/06/2020.

MASON, S. F. História da Ciência: As principais correntes do pensamento científico. Porto. Alegre: Editora Globo, $1^{\mathrm{a}}$ Edição, 1964.

MORIN, E. Et al. Para um Pensamento do Sul. In: ENCONTRO INTERNACIONAL PARA UM PENSAMENTO DO SUL, 2011, Rio de Janeiro, RJ, Anais. Rio de Janeiro: SESC, Departamento Nacional, 2011. p. 20 a 35.

MORIN, E. A CABEÇA BEM-FEITA: repensar a reforma, reformar o pensamento. Trad. Eloá Jacobina. Rio de Janeiro: Bertrand Brasil, 2007.

. Ciência com consciência. Trad. Maria D. Alexandre e Maria Alice Sampaio Dória. 13ª edição. Rio de Janeiro: Bertrand Brasil, 2010.

.; CIURANA, E. R.; MOTTA, R. D. Educar na era planetária. Tradução: Sandra T. Valenzuela. Revisão técnica: Edgard de Assis Carvalho. São Paulo: Cortez; Brasília, DF: UNESCO, 2003.

Introdução ao Pensamento Complexo. Trad. Eliane Lisboa. Porto Alegre: Editora Sulina, 2007a.

O método 1. A natureza da natureza. Trad. Ilana Heineberg. Porto Alegre: Sulina, 2008. 
Sulina, 2011a.

O método 2. A Vida da Vida. Trad. Marina Lobo. Porto Alegre:

O método 3.O Conhecimento do Conhecimento. Trad. Juremir Machado da Silva. Porto Alegre: Sulina, 2008a.

O método 4. As ideias. Trad. Juremir Machado da Silva. Porto Alegre: Sulina, 2011b.

O método 5. A Humanidade da Humanidade. Trad. Juremir Machado da Silva. Porto Alegre: Sulina, 2002.

O método 6. Ética. Trad. Juremir Machado da Silva. Porto Alegre: Sulina, 2007b.

; KERN, Anne Brigitte. Terra-Pátria. Trad. Paulo Neves. Porto Alegre: Sulina, 2011.

ONU. A ONU e a mudança climática. Disponível em: https://nacoesunidas.org/ acao/mudanca-climatica Acesso em 02/07/2020.

PACTO MUNDIAL DE JOVENS PELO CLIMA. Propostas de estudantes das escolas de São Paulo, Brasil. Disponível em: https://www.globalyouthclimatepact. org/docs/proposals/2016-pact-brasil_Propuestas-Sao-Paulo.pdf Acesso em 14/08/2020.

PETRAGLIA, I. C. "Olhar sobre o olhar que olha": complexidade, holística e educação. Petrópolis: Vozes, 2001.

VATICAN NEWS. Disponível em: https://www.vaticannews.va/pt/vaticano/ news/2018-06/anuario-pontificio-2018-annuarium-statisticum-ecclesiae.html Acesso em 02/07/2020. 